\title{
Microstructural changes in alkali activated fly ash/slag geopolymers with sulfate exposure
}

\author{
Idawati Ismail · Susan A. Bernal • \\ John L. Provis • Sinin Hamdan • \\ Jannie S. J. van Deventer
}

Received: 8 June 2012/ Accepted: 26 June 2012/Published online: 11 July 2012

(C) RILEM 2012

\begin{abstract}
Sulfate attack is recognized as a significant threat to many concrete structures, and often takes place in soil or marine environments. However, the understanding of the behavior of alkali-activated and geopolymer materials in sulfate-rich environments is limited. Therefore, the aim of this study is to investigate the performance of alkali silicate-activated fly ash/slag geopolymer binders subjected to different forms of sulfate exposure, specifically, immersion in $5 \mathrm{wt} \%$ magnesium sulfate or $5 \mathrm{wt} \%$ sodium sulfate solutions, for 3 months. Extensive physical deterioration of the pastes is observed during immersion in $\mathrm{MgSO}_{4}$ solution,
\end{abstract}

I. Ismail · S. A. Bernal · J. L. Provis $(\bowtie)$.

J. S. J. van Deventer

Department of Chemical \& Biomolecular Engineering, University of Melbourne, Melbourne, VIC 3010, Australia

e-mail: j.provis@sheffield.ac.uk

I. Ismail

Department of Civil Engineering, Universiti Malaysia

Sarawak, Kota Samarahan, Sarawak, Malaysia

Present Address:

J. L. Provis

Department of Materials Science and Engineering,

University of Sheffield, Sheffield, UK

\section{S. Hamdan}

Department of Mechanical Engineering, Universiti

Malaysia Sarawak, Kota Samarahan, Sarawak, Malaysia

\section{J. S. J. van Deventer}

Zeobond Pty Ltd., PO Box 210, Somerton, VIC 3062, Australia but not in $\mathrm{Na}_{2} \mathrm{SO}_{4}$ solution. Calcium sulfate dihydrate (gypsum) forms in pastes immersed in $\mathrm{MgSO}_{4}$, and its expansive effects are identified as being particularly damaging to the material, but it is not observed in $\mathrm{Na}_{2} \mathrm{SO}_{4}$ environments. A lower water/binder $(w / b)$ ratio leads to a greatly enhanced resistance to degradation by sulfate attack. Infrared spectroscopy shows some significant changes in the silicate gel bonding environment of geopolymers immersed in $\mathrm{MgSO}_{4}$, attributed mostly to decalcification processes, but less changes upon exposure to sodium sulfate. It appears that the process of 'sulfate attack' on geopolymer binders is strongly dependent on the cation accompanying the sulfate, and it is suggested that a distinction should be drawn between 'magnesium sulfate attack' (where both $\mathrm{Mg}^{2+}$ and $\mathrm{SO}_{4}{ }^{2-}$ are capable of inducing damage in the structure), and general processes related to the presence of sulfate accompanied by other, non-damaging cations. The alkali-activated fly ash/slag binders tested here are susceptible to the first of these modes of attack, but not the second.

Keywords Geopolymer · Fly ash · Slag · Alkali-activated $\cdot$ Sulfate attack

\section{Introduction}

The chemical mechanisms that can lead to degradation of concretes include leaching of paste components, carbonation of calcium hydroxide and calcium silicate 